\title{
Solutions and frictions in civic hacking: collaboratively designing and building wait time predictions for an immigration office
}

\section{Sung-Yueh Perng \& Rob Kitchin}

To cite this article: Sung-Yueh Perng \& Rob Kitchin (2018) Solutions and frictions in civic hacking: collaboratively designing and building wait time predictions for an immigration office, Social \& Cultural Geography, 19:1, 1-20, DOI: 10.1080/14649365.2016.1247193

To link to this article: https://doi.org/10.1080/14649365.2016.1247193

\section{Published online: 21 Oct 2016.}

Submit your article to this journal ¿

III Article views: 429

Q View related articles ¿

View Crossmark data $[\pi$

Citing articles: 11 View citing articles 


\title{
Solutions and frictions in civic hacking: collaboratively designing and building wait time predictions for an immigration office
}

\author{
Sung-Yueh Perng and Rob Kitchin \\ National Institute for Regional and Spatial Analysis, Maynooth University, Maynooth, Ireland
}

\begin{abstract}
Smart and data-driven technologies seek to create urban environments and systems that can operate efficiently and effortlessly. Yet, the design and implementation of such technical solutions are full of frictions, producing unanticipated consequences and generating turbulence that foreclose the creation of friction-free city solutions. In this paper, we examine the development of solutions for wait time predictions in the context of civic hacking to argue that a focus on frictions is important for establishing a critical understanding of innovation for urban everyday life. The empirical study adopted an ethnographically informed mobile methods approach to follow how frictions emerge and linger in the design and production of queue predictions developed through the civic hacking initiative, Code for Ireland. In so doing, the paper charts how solutions have to be worked up and strategies re-negotiated when a shared motivation meets different data sources, technical expertise, frames of understanding, urban imaginaries and organisational practices; and how solutions are contingently stabilised in technological, motivational, spatiotemporal and organisational specificities rather than unfolding in a smooth, linear, progressive trajectory.
\end{abstract}

\section{Solutions et frictions dans le domaine du piratage civique : création et construction collaborative de prédictions d'attente pour un bureau d'immigration}

\section{RÉSUMÉ}

Les technologies intelligentes fondées sur les données tentent de créer des environnements urbains et des systèmes qui puissent fonctionner efficacement et sans effort. Pourtant, la création et la mise en place de telles solutions techniques sont pleines de frictions, produisant des conséquences non anticipées et générant des agitations qui empêchent la création de solutions urbaines sans friction. Dans cet article, nous examinons le développement de solutions pour les prédictions de temps d'attente dans le contexte du piratage civique pour soutenir que l'accent mis sur les frictions est important afin d'établir une compréhension critique de l'innovation pour et dans la vie quotidienne urbaine. L'étude empirique a adopté une approche de méthodes mobiles spécialisées en ethnographie pour suivre comment les frictions commencent et persistent dans

\section{ARTICLE HISTORY}

Received 10 December 2015 Accepted 26 September 2016

\section{KEYWORDS}

Frictions; solutions; civic hacking; smart city; postcolonial technoscience; Code for Ireland

\section{MOTS CLÉS}

frictions; solutions; piratage civique; ville intelligente; technoscience postcoloniale; Code for Ireland

\section{PALABRAS CLAVE}

fricciones; soluciones; piratería informática cívica; ciudad inteligente; tecnociencia poscolonial; Código para Irlanda 
la création et la production de prédictions de queue développées par l'initiative de piratage civique Code for Ireland. Ce faisant, cet article explore comment les solutions doivent être résolues et les stratégies renégociées quand la motivation commune rencontre des sources de données différentes, de l'expertise technique, des cadres de compréhension, des imaginaires urbains et des pratiques organisationnelles ; et comment les solutions sont stabilisées de manière contingente dans des spécificités technologiques, motivationnelles, spatiotemporelles et organisationnelles au lieu de se dérouler dans une trajectoire régulière, linéaire et progressive.

\section{Soluciones y fricciones en el hacking cívico: diseño colaborativo para predecir los tiempos de espera en las oficinas de inmigración}

\section{RESUMEN}

Las tecnologías inteligentes y basadas en datos buscan crear ambientes urbanos y sistemas que pueden operar de manera eficiente y sin esfuerzo. Sin embargo, el diseño y la implementación de este tipo de soluciones técnicas están llenos de fricciones, produciendo consecuencias imprevistas y generando tumulto que evitan la creación de soluciones libres de fricción en la ciudad. En este trabajo, se analiza el desarrollo de soluciones para las predicciones de tiempo de espera en el contexto de la piratería informática cívica para argumentar que un enfoque en fricciones es importante a la hora de establecer una comprensión crítica de la innovación para y en la vida cotidiana urbana. El estudio empírico adoptó un enfoque de métodos móviles etnográficamente informados para estar al tanto de cómo surgen las fricciones y permanecen en el diseño y producción de predicciones en lista desarrolladas a través de la iniciativa de piratería cívica, Código para Irlanda. De este modo, este documento grafica cómo las soluciones tienen que ser trabajadas y las estrategias renegociadas cuando una motivación compartida se encuentra con diferentes fuentes de datos, conocimientos técnicos, marcos de entendimiento, imaginarios urbanos y prácticas de organización; y cómo las soluciones se estabilizan en forma contingente en especificidades tecnológicas, de motivación, espacio-temporales y de organización, en lugar de desplegarse en una trayectoria lineal, calma y progresiva.

\section{Introduction}

Civic hacking binds together elements of civil innovation and computer hacking, with citizens quickly and collaboratively developing technological solutions, such as creating new apps, to address local issues (Levitas, 2013). As such, civic hacking has enriched the original meaning and purposes of 'hacking', transforming itself into alternative place-making practices through which innovative technologies can be appropriated by'smart' citizens and communities to re-create urban governance, community engagement, and the meaning and practice of urban everyday life (Townsend, 2013). Hacking in its early history had an emphasis on playful and creative tinkering with digital technology, and was often associated with subversive activities such as cybercrime and cyberattacks by the media and public (Levy, 1994). Subsequent development has seen free and open-source software community 
(F/OSS) incorporating and expanding the ethics of hacking, with hacking positioned more broadly towards improving software code, products and deployment. Civic hacking initiatives largely align themselves with F/OSS in that the ethical opportunity of transparency of data, code and governance is upheld. The liberal cultures and sensibilities of the F/OSS communities are also cultivated and registered through highlighting the benefits of releasing data from otherwise locked down systems or formats and sharing source code to encourage wider business or civic uptake and reuse (Coleman, 2013). Nonetheless, as Coleman also notes, the values, practices and ethics of hacking are varied, embodied and contested within civic hacking events given the diverse positions adopted by community members and the unfolding cultivation of trust and working relationships between them.

The new possibility of collaborating with governments through the practice of civic hacking and finding alternative solutions to urban issues raises many concerns, including the incorporation of certain modes of governmentality, ideology, epistemology and mythology within the discourses of smart city and big data analytics. With respect to governmentality there is an underlying belief in the politics of calculation and technocratic solutionism. In the former, a highly calculative, rational and instrumental thinking is promoted as a 'progressive' and desirable mode of governance (Elden, 2006). This instrumental framing of state and urban development is refreshed by the growing emphasis on the potentials of incorporating data, software and other information technologies into the collaboration between citizens and local governments. Cities are conceived as sets of data, charts and analytics results, and engineered as if they could be effectively managed, effortlessly lived, globally connected and generically replicated elsewhere (Vanolo, 2013; Wiig, 2015). This is accompanied by a belief in technocratic solutionism wherein the problems of the city are tackled through technical fixes, rather than political/social solutions and citizen-centred deliberative democracy (Mattern, 2013; Morozov, 2013). These technical solutions often treat cities as ahistorical and aspatial and as generic markets, promoting one-size fits all fixes rather than recognising the need for bespoke solutions tailored to city characteristics and needs. Moreover, the technologies deployed are portrayed as being objective, commonsensical, pragmatic and politically benign, rather than thoroughly political, reflecting the views and values of their developers and stakeholders (Kitchin, 2014; Kitchin, Lauriault, \& McArdle, 2015). These discourses, while predominately designed to promote corporate solutions to city management and governance (Söderström, Paasche, \& Klauser, 2014), also enthuse civic hacking to turn to software and data for solving urban problems.

Further, similar to other citizen-led initiatives, civic hacking can produce uncertain results and even deepen existing social, technical and demographic barriers for participation. While civic hacking possesses potential values for delivering innovative city services, it remains unclear as to how social, cultural, economic or governmental values can be distributed fairly; how its long-term impacts can be examined critically; and the extent to which governments can withdraw their responsibility of providing services to citizens (Johnson \& Robinson, 2014). In addition, technical requirements to perform certain kinds of 'hacking' can demand sufficient levels of skills, resources, commitments and knowledge and reproduce the hierarchy of, rather than democratise, civic participation (Haklay, 2013; see also Elwood, 2010). Particularly in the context of creating 'smart' solutions by citizens themselves, there is a tendency towards the 'widgetization' of urban problems, resources and interests wherein complexly intertwined aspects of a city (infrastructure, data, web portals, built environment, lived experiences and forms of knowledge) are reduced into thematic widgets that represent the interests of the individuals capable of making them (Mattern, 2014). 
We contribute a geographic examination of civic hacking as a prominent urban practice of collaborative making of civic technology that has received little attention in the discipline to date. The analysis is set in dialogue with geographic research on participatory, crowdsourced and volunteered production of geographic information and knowledge and draws upon science and technology studies to make sense of civic hacking practices and their wider implications for alternative city and future making. We understand civic hacking by drawing on postcolonial technoscience to articulate the contingent, contextual and precarious relationships that are temporarily mobilised and give shape to a solution. Our focus concerns how solutions are worked up during their uneasy encounters with participants, technological innovations and local governments, rather than possessing predefined qualities and effects to change the city. We conceptualise solutions as cultural and technological productions resulting from distributed interactions between persons, things and practices, and in relation to the spatiotemporal contexts of the occurrences (Gell, 1998; Mackenzie, 2006). Further, we investigate how a solution can take multiple forms and are continuously reconfigured according to differently mobilised and assembled technologies, interests, skills and the public (de Laet \& Mol, 2000; Sheller, 2004; Urry, 2007). To this end, we trace the biographical trajectories of a solution pursued in Dublin under the civic initiative of Code for Ireland and unpack the multiplicity of the solution by exploring how it changed throughout the course of meetings between Code for Ireland participants and local government offices. In particular, the metaphor of 'friction' is explored to show how solutions change and become charged during their encounters with diverse participants, skills, motivations, rules and sociotechnical imaginaries.

The remainder of the paper starts with suggesting how postcolonial technoscience, and the notion of friction in particular, provides a critical lens to understand civic hacking as an emerging urban cultural practice and a process of appropriating technology innovation to address community issues by its members. We then discuss the mobile method of 'following the solution' used in the study and provide a brief introduction to the civic hacking project the paper examines, before analysing in detail the process of developing solutions and the frictions that emerge. Throughout the paper, we articulate the messy relationships between government agencies, technologists participating in civic initiatives, openly created and shared code and different expectations involved in shaping 'the solution'.

\section{Innovations, solutions and frictions}

Within civic hacking, the processes of identifying problems, innovating solutions and implementing strategies are not smooth and can be full of negotiations, tensions and compromises. They occur in citizen initiatives where design methods, computer-supported collaboration techniques, deliberative processes and technological objects are reconsidered and reappropriated for transforming everyday practices into ways of informing the making of future cities, communities and collaborative crisis response (Forlano \& Mathew, 2014; Powell, 2008; Starbird \& Palen, 2011). These tensions and negotiations are not particular to civic appropriation of technology. In postcolonial writings on knowledge and innovation, there has been an emphasis on how science and technology develop and travel instead of deriving from fixed and centred points of departure of ideas, values and practices (Pigg, 1992). Early reflections critiqued the focus of science studies on the histories and developments of the West, and proposed 'provincializing Europe' by foregrounding the local, multiple 
and contingent reconfigurations of modern technologies and knowledge in (post)colonial locations (Chakrabarty, 2000; Harding, 1994). The descriptions, claims and ideologies that justify universalist reasoning, standards, applicability and imagination of technological pasts and futures are also called into question (Anderson, 2002). Approaching the global flows of knowledge and innovation this way, the practical steps for achieving shared futures cannot be understood as dissolving technical or epistemic differences to create sameness across locations. Rather, they are moments and practices where partially compatible, but sometimes incomparable, 'times-places' of the frames of understanding, embodied performance of scientific practices (e.g. enumeration and generalisation) and disparate origins and manifestations of commodities and markets are transferred, displayed, translated or brought into 'good enough merely for a few here-and-nows' for seeking alternative relationships, life and futures (Verran, 2002, p. 750, 2010).

The emphasis on the distributed, multiple and contingent reconfigurations of technology in postcolonial technoscience is productive for conceptualising civic hacking. There are multiple 'here-and-nows' that attach hopes to the purposes of civic hacking by different actors, for example programmers, community members, organisers, governments or the general public. However, they at the same time inadvertently bring constraints and uncertainties into the process of shaping technologies for civic purposes. Highlighting this aspect, we further turn our attention towards the precariousness and messiness around working up any solution and making progress when innovating civic technologies. That is, the 'universalist' discourses and sociotechnical imaginaries around solutions require further work to unpick how they become situated in specific civic purposes and community dynamics, as well as in particular'technology-in-use' for challenging the notion of innovation's universal applicability (Edgerton, 2010).

This way of rethinking solutions and progress requires shifting our focus towards 'frictions' and to explore how civic hacking initiatives are set in motion during their encounters with different times-places, frames of understanding and forms of practices. The notion of friction is initially proposed to understand the global connections of science, capitalism and politics and how the pursuit of their universal dreams, claims and knowledge are situated in the friction-rich encounters with local communities, cultures and natural environments. These global connections attempt to achieve their claims of universality by acquiring content and force within specific historical and local conjunctures. To become universal is to travel across differences. Here, differences are key to community collaboration because they energise participating individuals, organisations and motivations through affirming a shared frame for making connections within participating organisations and acting as a medium for the collaboration to find local purchase:

Social mobilizations are also held up and redirected by their inclusion of varied groups, who disagree about what are supposed to be common causes and objects of concern. In this process, universalist causes are locally reconfigured, even as they are held by a wider-reaching charisma. (Tsing, 2005, pp. 245, 246)

Thus, encountering with local specificities becomes an important site, where widened and new arrangements of knowledge, cultures and ideas emerge, which change and charge them, enabling them to move across different cultural aspirations, and yet with the impossibility to specify definite courses and consequences:

Friction makes global connection powerful and effective. Meanwhile, without even trying, friction gets in the way of the smooth operation of global power. Difference can disrupt, causing everyday malfunctions as well as unexpected cataclysms. (Tsing, 2005, p. 6) 
Re-framing global connections and local collaboration this way, Tsing points towards the importance of not assuming a singular discourse, meaning and arrangement that the universal takes to progress its influence on the local. Instead, the focus of analysis on the claim of universalism can take on the fragmentary processes of globalisation that are unevenly achieved, contested, redirected or suspended in and through the'sticky materiality of practical encounters' (Tsing, 2005, p. 1).

Focusing on frictions and how universalising forces change and recharge in practical encounters, we are also drawn into observing various kinds of conceptual and practical 'relocations' necessary for innovation (Suchman, 2011). The 'place' of future-making can be reconsidered by exploring how it is situated in contingent and uncertain situations. A knowledge- and investment-intensive hub of innovation is enacted by particular and specific sociomaterial arrangements to sustain it as a precarious centre (Redfield, 2002). Also, the 'origin', the defining moment and the 'progressive' trajectories of development all have to be critically re-examined to attend to the promises and imaginaries articulated through and enabled by the practices and micropolitics within design and innovation (Suchman, 2011). More often than not, mis-aligned aims, identities and practices lead to negotiations that acutely reveal that 'progress' is seldom a streamlined and linear process. Willing and unwilling adjustments have to be made in order to draw out a solution that can be accommodated by differently involved individuals, cultures and organisations (Davies, Tybjerg, Whiteley, \& Söderqvist, 2015). These misalignments further make explicit the importance of considering how the sociotechnical imaginaries associated with technological innovation - its designed futures, purposes and effects - can be reshaped by problematising the social, local, contextual, temporal and epistemological positions, where future-making takes place (Dourish \& Mainwaring, 2012; Philip, Irani, \& Dourish, 2012). As a result of relocating the place, origin and progress of innovation, it also becomes necessary to rethink the framing of its products and achievements by taking into account how progress is situated in tricky encounters with local specificities or how'productive confusion' can be'the most creative and successful form of the collaborative production' (Tsing, 2005, p. 247).

Accordingly, the progress of future-making in the city is inevitably situated in the precarious and contingent relationships with technological systems of all range of scales. From travelling within the city to conducting large-scale surveillance, software continuously and imperfectly mediates how we understand and formulate problems, which in turn influences how solutions are planned and exercised. That is, there is no direct, linear relationship between problems, solutions and the place in which they are deployed (Kitchin \& Dodge, 2011). These relationships are citational and performative, in that problems are constantly remade according to how they are articulated and materialised in relation to their social and spatial contexts. Sociotechnical systems arranged accordingly are thus incomplete solutions to a relational problem, and are effective only temporarily because problems are constantly and yet partially remade. This partiality of solutions can also be revealed when they are pursued. As Urry's (2014) reworking of wicked problems argues, the effort of designing and producing future cities is always situated in complex interdependencies in which one solution reveals or creates further problems, and the conditions of defining problems and sourcing solutions can inform each other and change over time.

Understanding civic hacking through the lens of frictions, we articulate the encounters among the individuals, governments, technologies and lines of code enmeshed together through the Code for Ireland initiative. The analysis provides an initial analysis of the frictions 
emerging from such encounters and the different kinds of problems that are only partially solved, as well as new ones that have to be dealt with when the project carries on.

\section{Methodology}

Inspired by the ethnographically informed approach of mobile methods (Büscher, Liegl, Perng, \& Wood, 2014; Büscher, Urry, \& Witchger, 2011), we 'follow the solution' to explore how it develops and changes during its encounters with frictions. This means that we shadow, physically and virtually, the where, when, with whom and with which cultural and technological objects and imaginaries frictions emerge and linger. We trace and track the processes in which solutions have to be worked up when a shared motivation meets diverse skills, perspectives, designs or software code under the context of civic hacking meetups. This research method is productive in two ways. It recognises that knowledge and practice are intimately embedded in multiple, physical and virtual sites, such as face-to-face meetups, virtual meetings in between and discussion in online collaboration websites (Hine, 2000; Marcus, 1995). More importantly, the method enables the exploration of the contingent and continual shaping of solutions and how they change during their encounters with heterogeneous sets of actors that are assembled contingently: urban problems and complexity, participants and their skills, and the relations and reconfigurations of technology. Making progress, civic hacking projects have to draw as much on the social interactions and discussions in these sites, as on the capabilities of the technologies involved in the projects, expectations for them, documentation about them, places where these technologies are expected to effect, and organisational regulations related to these places. In other words, the effects of civic hacking should be examined relationally by taking into account humans, objects, technologies and the contexts where they reconfigure one another (Gell, 1998).

Furthermore, the method draws out how these interactions and processes of working up solutions are performative and citational, enacting and focusing on some of the problems during particular encounters, while leaving others to arise in other social, urban and technical contexts. This is particularly the case when examining the relationship between software, data and the city. Any problem, knowledge and practice associated with them can only be imperfectly formulated and thus solutions are constantly revisited when previously unknown or unacknowledged aspects of a problem become known or are made explicit (Kitchin \& Dodge, 2011). Accordingly, by following solutions, we are able to gain insights into how solutions derive from and draw on the continuous and contingent shaping of their relationships with problems, participants' knowledge and skill, and the sociotechnical imaginaries of urban futures pursued and contested in the process of technology innovation.

We focus our analysis on the 'MyQ.ie' project, one of the earliest projects in the Code for Ireland initiative, the Dublin chapter of the global 'Code for' movement. We focus on Dublin and Code for Ireland as the research site because of its explicit focus on developing smart, data-driven techniques for civic purposes. With the launch of Code for Ireland and several initial projects proposed by members living in Dublin, there have been many and varied attempts and arrangements made by participants to develop civic technology according to community needs, available data-sets and organisational concerns. Given the diversity of participants, these varied attempts are full of contingent, multiple 'here-and-nows' where values, concerns, imaginaries or temporalities are not necessarily compatible with one another (Verran, 2002). 
Following these solutions and frictions required us as researchers to physically attend the monthly'meetups', which we did between February 2014 and May 2015. The meetups took place in the headquarters of different multinational tech companies in central Dublin. At the meetups, technologists and people in the community or government meet, network, identify problems, explore possible solutions and then attempt to develop these solutions. We participated in the discussion to flesh out ideas and explore solutions, as well as informal conversations to understand the motivations and backgrounds of participants. We also followed how the ideas are worked on in between meetups, either through independent work or email and phone exchanges. Similar to other civic initiatives, by maintaining virtual collaborative work desk (Starbird \& Palen, 2013) tasks are distributed and wait to be picked up by participants using a variety of tools including Trello boards, Google Documents and Google Hangout. Supplementing the data from the observations made at the meetups and extracted from documents, we also conducted mobile ethnography on other Code for Ireland projects and four other civic hacking events in Dublin to trace the development and challenges of working on civic hacking projects.

\section{The 'MyQ.ie' project}

One of the projects whose development we followed is 'MyQ.ie' (https://MyQ.ie), which sought to create a web application to address the problem of long queues at an immigration office in Dublin. As one of the initial projects pursued by Code for Ireland when launched in January 2014, MyQ.ie has attracted considerable attention and contribution from Code for Ireland participants, and was the earliest project to be released to the public for testing and to attract further support. The selection of project idea was bottom-up and 'driven by citizens' (Levitas, 2013), reflecting the core value of Code for Ireland and its extension of the liberal sensitivities of earlier F/OSS practices and communities. Before the launch of the initiative, there had been preliminary meetups, where project ideas were proposed by the attendees and they voted on which projects to support and pursue.

The idea and rationale behind the project emerged because Dublin and Ireland have become important immigration destinations in Europe and globally, receiving just under 1 million new arrivals between 2000 and 2012 (Gilmartin, 2013). The project leader is an immigrant who shares a similar sense of frustration with nearly 90,000 other non-EU immigrants living in Dublin (Central Statistics Office, 2011) with respect to the long wait at the Garda National Immigration Bureau (GNIB) office where immigration registration and renewal take place. For these people, a trip to the GNIB office in Dublin requires a pre-registration for the day of their visit, arrival on the day to collect a number ticket and then a long wait to be called before an application is processed. The GNIB office runs a first-come-first-served system and the queues can start to form outside of the office well before it opens. The experience has been a collectively shared pain, and social media are often the place where applicants express their discontent, often in sarcastic ways. One applicant started queuing around $6.25 \mathrm{am}$ and tweeted that they felt 'awesome' being in 'the first 10 people' in the queue, and another commented ironically on the growing international community 'known as the \#GNIB'. ${ }^{1}$ To make things worse, people can wait in the queue only to realise that the quota for the kind of visa they want to apply for has already been used up on that particular day, so they have to come back on another day. The only way to find out if there is still a visa available is by staying and waiting in the queue to receive the verdict. The aim of the 


\section{How will we do it?}
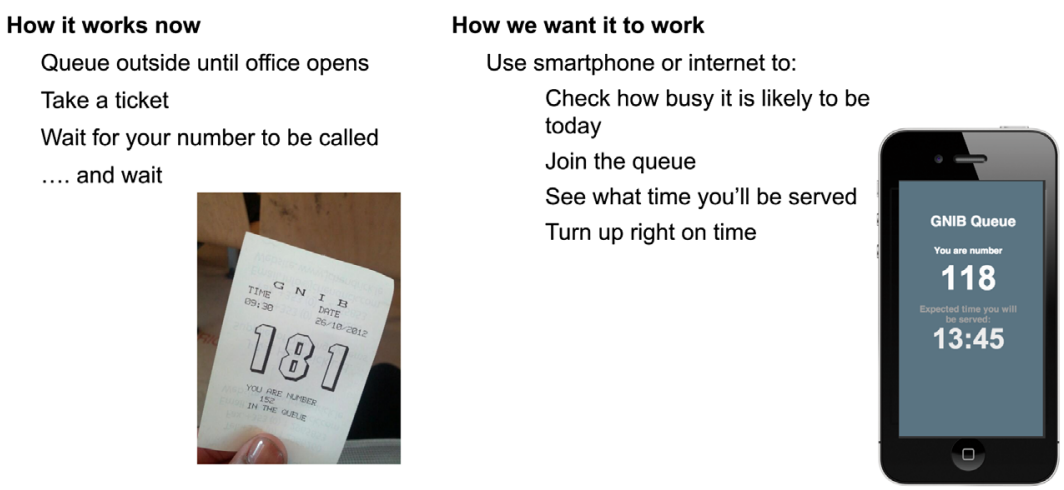

Figure 1. GNIB queue solution. Reproduced with permission of Mark Montgomerie on behalf of Code for Ireland.

MyQ.ie project is to manage the pain of queuing at the GNIB office by providing an estimate of queuing time, as demonstrated in Figure 1, so that these applicants can have better use of their time, or simply wait elsewhere and return to the office when it is their turn.

However, personally participating in the queuing process was not a prerequisite to join the project, nor a shared experience among the participants. Many project members are Irish, if not coming from another EU country and not required to apply for a permit to stay. The lack of shared experiences was not a barrier, and the project had sufficient participants and skills to bring the app to the stage of public testing. The project members were motivated by the possibilities they observed in the proposed solution of scaling up or moving across to other governmental, public or private sites that are not yet equipped with such technology. The techno-utopian tendency that Wiig (2015) observes can be found replicated in the solution proposal and shared motivation to pursue it. However, 'the solution' is not a stable construct and very quickly started to go through a number of sessions of brainstorming, discussion, negotiation and revision. After the first two meetups, the participants identified their working solution to be the design and implementation of a queue time estimation for the GNIB office. They planned to create an API to transform the data they obtained via a Google form, process them in a spreadsheet to validate the input, and calculate the wait time by considering a range of factors (e.g. day of the week, numbers of tickets issued already, average processing time per ticket on the day, etc.). The validation and calculation result can then be viewed in a dynamically refreshed webpage to show when each ticket holder is likely to be served, and in the app version push notifications can be sent to the users reminding them to go back the GNIB office.

\section{Developing initial solutions}

The project started by sizing up different types of data that the GNIB office might have and how these data could potentially be transformed into useful estimations. In this process, the 
calculative and instrumental rationality, often observed in state and corporatised governance (Elden, 2006; Söderström et al., 2014), also becomes a strategy that civic hacking adopts to intervene in the queuing problem. It materialises as a 'calculative impulse' through the emphasis of the project in excavating data from possible sources, social and governmental alike, analysing the patterns of the queue, and subsequently developing prediction-based technical fixes for it. But at every step of the way, this 'calculative impulse' encountered sociotechnical specificities of the queue that challenge, change and charge the project.

The first challenge for the project was the difficulty of turning chaotic queues and the obscure, if not entirely unavailable, sources of data into a streamlined process of estimation. Clues from the photos of the ticket, which applicants received at the GNIB office and circulated via social media (e.g. Foursquare and Twitter), were worked on to extract useful information during the initial stage of the project when communication with the relevant governmental office had not been established. A GNIB ticket, photo on the left in Figure 1, details the date and time when the ticket was issued, the number assigned to an applicant, and the number in the queue. From these data, the following information can be deduced: the number of applicants arriving before a specific ticket is issued (from the assigned number) and the number of applicants who are still waiting to be served (number in the queue). Also, the date and time provide contextual information about how long the office has been open and the speed of processing applications on that day.

The information extracted from ticket photos becomes a necessary starting point to understand the quality of estimation from social media data. The use of social media images is not without concern. For example, there are questions concerning their credibility, reliability and quality as data sources, as with other sources of volunteered geographic information (Sui \& Goodchild, 2011). In many other situations, inaccessible file formats such as .jpg or .pdf causes issues of interoperability and can hinder subsequent parsing, analysis and reuse of the data, particularly when computational means can be put in place to assist the process. But the inaccessibility of the images in this particular context provides integrity and reliability to the images as data sources. In these images, the date, time and numbers can be clearly captured and the likelihood of them being altered is relatively small. However, the issue with photos available on social media is that the sample size is too small to provide an accurate estimation, let alone responding to the dynamics of the queue. Busy hours and seasons, or the complexity or trickiness of particular applications, can seriously affect the time other applicants have to wait. The logical solution to this is to enlarge the sample pool. The project team thus determined that it was critical to contact the GNIB and the police and to try and persuade them to release more data.

At the same time, project participants worked out another sociotechnical arrangement to fix the issue of data size and to ensure the credibility of the data-set, which created its own problem. A Google form was designed, allowing GNIB applicants to upload their ticket details via the form for the project to expand the data-set by crowdsourcing the data. However, by replacing photos with an online data entry form, the physical correspondence between sources of data (pictures saved on computer) and the extracted information (e.g. applications already processed speed of the day) becomes uncertain. This raises considerable concerns over the validity of each data entry and the reliability of the information, and ultimately the calculation of wait time. Thus, other mechanisms have to be in place and a Google spreadsheet was created to validate and process data obtained via the form. 
A Google spreadsheet containing a series of columns was created to calculate the credibility and value of the raw social media and later volunteered data, before generating any insight about the queue. Opening hours on different days of the week are kept in one sheet and the raw data gathered from pictures shared in social media in another. As partially captured in Figure 2, the main spreadsheet, aptly entitled 'Calculations', comprises logical operators, mathematical formulae and Google spreadsheets functions that incorporate data and information from various spreadsheets. By doing this, the spreadsheet seeks to test and train their operators and formulae for determining the quality of data and working out how to best use the extracted data for calculating wait time. The initial block of columns incorporates raw and dummy data for subsequent calculation. The second block of columns aims to determine the quality of the data, as well as testing if the logical and arithmetic functions can separate dummy data from the data extracted from real tickets found in social media. At the end of this block of columns, Column P, a score is assigned to each row of data after taking into account several aspects of the ticket and the queue for data quality evaluation. These aspects include whether the numbers related to the queue are entered correctly; if a ticket is taken too early in the day to tell how the queue progresses that day; if the data are provided when the applicant is in the queue; or if the ticket is taken within the opening hours. Each of these aspects is transformed into a TRUE or FALSE statement in the columns leading to Column $\mathrm{P}$, where a score is given by counting the number of FALSE between Column $\mathrm{G}$ and $\mathrm{O}$ to determine the data quality of each row.

These aspects of a ticket are further worked on in the last block of columns to create various kinds of expectations regarding how valuable insights extracted from them can streamline the queue in the GNIB office. The 'intelligence' that can be extracted from a single ticket can tell if it is near real-time queue data; if someone is providing fake data; how the progress of a particular day compares with others; how the variation of processing speed affect wait time on that specific day, which days, hours or seasons are more congested than others; or how a particular ticket should be given more'weight' in the process of estimating wait time.

Tracing and tracking the initial development of civic solutions to the long queue at the GNIB office, we observe various ways in which, drawing upon Dourish and Mainwaring (2012) and Vanolo (2013), a 'calculative impulse' seeks to govern civic hacking: the queuing problem is hopefully to be streamlined and understood in terms of queue tickets; the emphasis is placed on collecting, generating and analysing data about the queue as fixes for the long wait at the immigration office; and there is an emphatic desire to calculate all possible aspects related to the queue for addressing the problem. This 'calculative impulse' enables people to interact and know local specificities, and is pursued by relating, re-ordering and removing

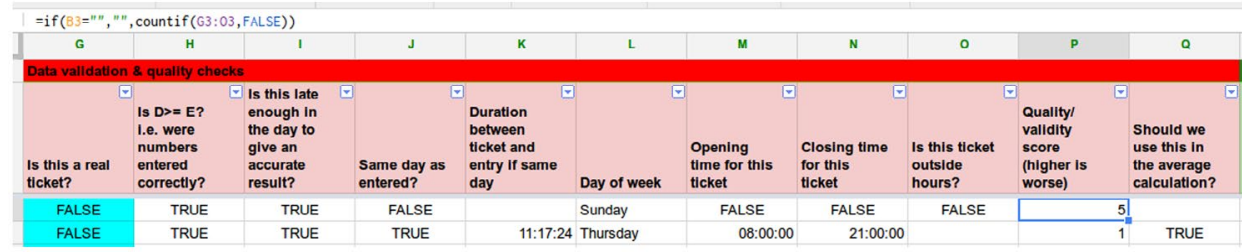

Figure 2. Becoming useful data. Reproduced with permission of Mark Montgomerie on behalf of Code for Ireland. 
(some of) these local elements to generate standardised knowledge and applications that are applicable and deployable elsewhere. It is enthused by the increasing emphasis in civic hacking and civic technology, in Dublin and in other global cities such as New York or Los Angeles, on disseminating and repurposing publicly available data-sets using new interactive interfaces and urban informatics to create a quantifiable community and instrumental city (Mattern, 2016). These approaches incorporate and prioritise'mathematical and numerical principles' and result in 'the reduction of aspects of everyday life to forms amenable to statistical analysis' (Dourish \& Mainwaring, 2012, p. 137).

Despite the universalising attempts of the calculative impulse in civic hacking, the projects are shaped contingently by the involved participants, technologies and digital objects, which resonate with the way in which the knowledge production of a geocoding subject is situated in technological, embodied and temporal specificities (Wilson, 2011). The initial solution of MyQ.ie arose from the accidental discovery of social media data, the subsequent attempt at data verification, and the lack of response from the GNIB office until this point. The spreadsheet for the project became stabilised as a solution because social media images were the richest points of contact with the people affected by the queue. Other resources they started with were rather limited, including the lack of response from the police, leading the design of the spreadsheet towards validating self-provided data. The effectiveness of the solution is thus heavily reliant on these encounters with the queue, the data and the calculative technique developed from them, and is only temporarily accepted before new possibilities emerge. Solutions therefore are better understood as 'fluid' sociotechnical arrangements (de Laet \& Mol, 2000) considering that they change according to how continual, oncoming challenges are folded into them.

Considered as social practices of volunteering skills, expertise and information (Elwood, Goodchild, \& Sui, 2012; Goodchild, 2007), civic hacking invokes its own hopes and politics when participants bring their aspirations for civic hacking, technical expertise and on-theground knowledge into their projects. MyQ.ie project gained considerable traction among Code for Ireland participants and attracted most of the software developers at the events to the extent of almost halting the progress of other projects. For the developers, while the images of the queue tickets from social media gave a head start to the project, it is still a technically challenging task to extract information about the queue from these very limited sources. However, the technical trickiness did not deter the participants, and particularly the developers felt the 'tick', as one of the project members commented, and continued to contribute their time and skills. Further, these participants are also socially motivated in that they recognise the ethical opportunity and prospect of improving the transparency of the GNIB office and the efficiency of the government by leveraging their technical skills.

Code for Ireland adopts the liberal ideas and values within F/OSS community (Coleman, 2013), with added emphasis on the notions and practices of transparency and inclusiveness, which are also crucial strategies for critical and participatory GIS and spatial technologies to engage with citizens (Elwood \& Leszczynski, 2013). Code for Ireland pursues their goal of being an inclusive and transparent organisation by encouraging the fluidity of project membership and open access to the technologies and knowledge emerging from the initiative (Maalsen \& Perng, 2016). This liberal sensitivity has been realised in the freedom of choosing the objectives and goals of a project that their participants agree with, the stage that project is at, and the skills they consider the project needs, as well as shaping the project collaboratively with other members once they join. 
However, the project also suffered from the liberal and fluid team membership. As the project progressed, the size of the group shrank and the main contributions to the project were driven by four participants who took on significantly more responsibility than others, a situation similar to other crowdsourcing activities such as OpenStreetMap (Haklay \& Weber, 2008; Mooney \& Corcoran, 2012). In the meanwhile, frustration and new hopes also emerged. At times, 'marketing strategies' were suggested to encourage GNIB applicants to upload their queue details, and at other times, frustration grew when proposals to relevant agencies for getting necessary data are perpetually under consideration. On these occasions, personal contacts with relevant departments are offered for making more contacts, alongside suggestions of trialling the prototype at other more receptive public offices.

\section{Making 'progress'}

From its inception, the project planned to initiate conversations with the police unit that oversees the GNIB office, and after many attempts a police officer, or a 'garda', attended one of the meetups. This was an exciting opportunity for the project to explore what data collection options would be realistic for improving wait time estimation. Before the meetup, the project members had prepared a document drafting their ideas, technical requirements and possible data-sets that the police might possess. However, this does not mean that the flows of conversation and the progress made during the day were carried out effortlessly. Rather than 'reaching consensus', the meetup unfolded through, following Verran (2002, 2010), disclosing disparate 'times-places' of the views, practices, regulations, expectations and technologies associated with the queue at the GNIB office and seeking to engineering various 'here-and-nows' as these differences are disclosed and incorporated partially or fully into the project. The meetup consisted of a series of probing and redirecting questions for the garda, and sustained frictions between the participants, technical fixes and organisations. Examining how the meetup unfolded, we demonstrate that frictions are more than 'crashes', 'glitches' or'mistakes' that break existing sociotechnical orders (Rose, 2016). Instead, frictions in civic hacking are generative encounters of confusion, unexpected cataclysms and reconfigurations of a universalising 'calculative impulse'. In what follows, we discuss in more detail how the project tried to advance the innovation but had to re-group after realising various social, technical and organisational complexities emerging from proposing one solution after another.

At the meetup, the project members were divided into two groups: one listening to project updates and the other explaining the project idea to the garda. However, as the field note below shows, while sympathetic towards the project, the garda was not sure about the rationale behind the initiative. The idea behind the project and its potential attractiveness to the police seems straightforward to its developers: by providing wait time estimation to applicants, the web application can reduce the stress of queuing and free up the time of both the people queuing and the staff fielding questions from those queuing. But police work is far from homogeneous, and from a community policing perspective this attractiveness was not obvious:

When I joined, the garda was listening to the project explaining its motivation, but he looked a bit confused. It was suggested that helping build the app could benefit the police because this can reduce the amount of work the police needs to handle when people come to ask for information or help. So he raised the point, from a community service's perspective, you would want people to come to talk to us. 
For community police, meeting with people in local communities face-to-face is an important mechanism because, as the garda further explained, it fosters the rapport between the police and the community. The burden from the project's perspective is actually an advantage that community policing seeks to establish.

At this point, the conversation continued, but with a slight change of focus that tried to more closely align the solution with the community policing perspective. This time, the emphasis was placed on exploring the possibility of setting up technical fixes to the IT system in the GNIB office and equipping it with the capability of automated queue data collection. This issue was discussed in both groups, one going through some technical possibilities and the other seeking feedback from the garda, before the groups merged into one. This topic had been a recurrent one, and many ideas were proposed. The group asked if the agency keeps any record of the number of applications received each day. However, the garda suspected that the ticket machine only does the issuing of tickets and is not connected to any application database. As a result, such records might not exist. This meant two different sets of tactics for the project. One was to convince the agency that granting the project access to the record, providing that it exists, has real benefits to applicants and the agency alike. This, however, might be a long process before receiving a response. Other participants also came up with different technical arrangements to extract data from the physical office, and in turn these tactics excited and disappointed the participants as they further proposed solutions and uncovered challenges.

The most exciting piece of information they uncovered was that the ticketing machine is a closed system and not connected to any application database. This was encouraging in the sense that, by only getting the numbers off the machine, security threats and privacy concerns can be greatly reduced: no personal data would be obtained, nor unintended and unauthorised access to immigration data would become possible due to the project. Further, this technical fix would allow the project to acquire near real-time data about the flows of the incoming applicants, and prediction results could adapt to the change of the flows constantly. Various strategies were then proposed to capitalise on the discovery. One project member suggested a hardware hack that taps into the ticketing system to count and time the issuing of tickets. Another proposed that they install a camera in the office to stream the image of ticket numbers shown on the digital display in the office for optical character recognition. A supplementary comment pointed out that the camera should be equipped with data exchange capabilities to send out the images. Inspired by the conversation, a fourth participant added that the camera could also show how crowded the office is in realtime, as well as the counters to see how many are taking applications and the rates of processing them.

However, the discovery of the ticketing system and the imaginaries around the proposed hardware hacks did not progress the project immediately. Elwood and Leszczynski (2013) observe that participatory production of geographic knowledge involves exploring ways of interacting with new spatial media technologies and tools to legitimise their knowledge claims. Such dynamics are equally important in the collaborative making of technology in civic hacking in that sociotechnical arrangements for solutions emerge from dialogical processes of imagining and probing to build mutual understandings between the participants and the government and to firm up potential solutions. Subsequent conversation and exploration about new technical arrangements for obtaining queuing data at the meetup further demonstrate this aspect. 
The idea of installing a camera in the office triggered privacy concerns because applicants can be unwillingly captured by the camera. Indeed, the angle of the camera can be adjusted so that it only captures the image of the digital display and nothing else, as one participant revised the plan. But the receptiveness of the agency was largely unknown and difficult to anticipate due to the organisational, jurisdictional and spatial intermingling of the office. The GNIB office is shared and jointly controlled by the Department of Justice and the police. Installing a camera in the physical office would involve planning and negotiating with both agencies, understanding the sensitivity levels of the space, their respective ticketing systems, different roles and functions performed by the staff, organisational willingness to collaborate or concerns over adopting a system which can be appropriated to evaluate efficiency. Even the details of the model and make of the ticketing machine or the digital display were difficult to obtain on the day of the meetup because it was a Saturday, outside of normal office hours when civic hacking events tend to happen. Furthermore, using existing infrastructure in the office would be the most cost-effective way to upload captured images for subsequent processing, but the Internet connectivity in the office is integrated with the stand-alone security system for the police, and to apply to gain access to the infrastructure would add another layer of difficulty were the strategy to be adopted.

After the discussion with the garda, the project members were far from convinced that crowdsourcing would be the most efficient strategy to acquire data, although this approach was firmed up as the strategy to pursue the project, given the lack of alternatives. It became apparent at this point that the hopes and potentials of the project had shrunk considerably, but in a way different from other crowdsourcing, hacking and participatory initiatives. Exclusionary practices, corporate interests and insufficient access to high connectivity, knowledge and technical expertise, can all contribute to form 'hacking hierarchy' and dictate the levels of intervention (Haklay, 2013; and more generally on the politics in information geography, see Graham, De Sabbata, \& Zook, 2015). In MyQ.ie project, requirements for deep and in-depth technical skills reduced as the project developed and demands for other skills grew. Subsequent plans for the project included putting on stickers or flyers in the GNIB office and cafés and shops nearby to encourage data donation. The project offered itself as an opportunity of learning when partnering with a front-end designer to rethink the targeted users and needs as part of course work. Also, Code for Ireland and MyQ.ie participants were encouraged to visit the GNIB office to submit a queue number to enlarge the data-set. In other words, in terms of the expertise and resources required for the continuation of the project, the level of requirements decreased as the project became more fully developed. However, there still remains a gap between the momentum the project generated, the decreased technological demands of the prototype, and equivalent support from the relevant government offices, whether in terms of providing data or integrating the prototype, or more fundamentally investigating the causes of the queue itself. Accordingly, the politics of engineering in civic hacking also materialises in these gaps, in the different prioritisation of data sources, expectations around proposed solutions and everyday life and organisational practices between civic hackers and the government. The politics of participation also materialises in negotiating tricky temporal restrictions: off-duty hours for civic participation instead of caring responsibilities, on-duty days for considering civic requests in addition to routine tasks, or extra time for researching and acquiring new skills for civic projects on top of other commitments.

By examining the'progress' of MyQ.ie, we observe that civic hacking is shaped by frictions arising from, on the one hand, making visible and reassembling previously unknown or 
disintegrated understandings of a shared urban issue and, on the other, relocating technological artefacts into new sociomaterial arrangements of purposes, practices, places, organisations and their respective imaginaries about the future of specific hacks in question or civic hacking more generally. Accordingly, civic hacking has deep interdependencies with the ways in which an urban problem is formulated and redressed differently, imperfectly enacted each time a solution and required sociotechnical arrangements for it are proposed. The experiences of waiting and getting through the wait are inseparable from the sociotechnical assemblages around where they take place, whether on a railway platform during transit (Bissell, 2009) or in a queue in our case. In the project, the participants opted for wait time prediction to manage the pain, which is accompanied by the looming danger of amplifying the 'datafication of urban problems' that already drives technocratic city governance (for more on datafication, see van Dijck, 2014). By taking a data-centred approach to focus the project and the purpose of contacting the government further fuel two interrelated believes that: one the one hand, data can reform urban governance when complete and fine-grained data are uncovered, released, processed and made available to the public, and on the other only problems that can be discussed in data's term, that is organisable by spreadsheets or databases, or made intelligible through visualisation and prediction, are actionable issues. However, as the project progressed, it becomes apparent that the initial framing of the solution only articulates the problem partially and only in relation to the data available at that time. When the conversation with relevant organisations was made possible, the difficulty of the datafication of urban problems became apparent. There were entangled and contradictory ways of understanding privacy, efficiency, data availability, organisational aims and everyday practices that were held differently according to how people and government experience and relate to the problem of queues. These differences and problems emerged dynamically when the participants arranged a way of acquiring data, only to reveal further complexities and complications concerning issues that they have to take into account. In this way, all of these concerns took their turn revisiting the rhetoric and ideological assumption about data and data analytics being accurate and objective (boyd \& Crawford, 2012), and further situated them in the ongoing struggles with and continuous reconfigurations of sociotechnical arrangements for a seemingly undemanding task of acquiring data.

\section{Conclusion}

This paper theorises civic hacking from the perspective of postcolonial technoscience by suggesting that solutions have their own winding, friction-rich journeys before they are stabilised. Even when stabilised, solutions rely on temporary and precarious sets of sociomaterial arrangements for them to be carried out and to mobilise other participants and government or non-government organisations. By shifting the focus towards frictions that emerge from the sticky and messy encounters with urban complexity, we demonstrate that making progress within civic hacking projects and the effects they produce do not unfold in a smooth, linear, progressive trajectory. This is due to the fact that urban issues can only be partially and imperfectly translated into recognisable problems to solve, and that solutions developed from these problems can reveal or lead to further complications. Indeed, identifying and developing a solution involves a certain level of streamlining the problem, its solutions, the tactics and in some cases operation procedures. But the practice of streamlining becomes a key element that reveals the complex interdependencies between 
problems and solutions. Accordingly, solutions become effective because of the encountering with messy materialities, and there can be wider, unacknowledged or unanticipated events that occur and reveal the precariousness of any solution, as well as creating subsequent and new problems.

Bringing frictions into understanding civic hacking and solutions can have wider implications for rethinking how cities are innovated according to data and technology, or turned towards 'Lifeworldlnc' (Thrift, 2011). Recognising 'the incompleteness of cities' (Sassen, 2012) is a beginning of disclosing the interdependencies of a problem when solutions are designed to sensitise and respond to frictions emerging from relocating sociotechnical arrangements and expectations to solve the problem. Understanding civic hacking in terms of friction then foregrounds that its solutions are contingently stabilised in technological, motivational, spatiotemporal and organisational specificities, and that a progressive trajectory of development is far less important than articulating what are the people, skills, technological requirements, organisational cultures, and frames and understandings of problems that are enabled, particularised, marginalised, sidelined or excluded in the course of designing, innovating and mobilising specific solutions. More importantly, these misalignments or contradictions can emerge from the streamlined solutions encountering technical, urban and organisational systems that are too complicated and entangled for a civic initiative to tackle in full. Accordingly, on the one hand, the creativity and innovation in everyday life have to be recognised by taking into account the frictions occurring from challenging this complexity. On the other, taking these frictions seriously, designs and innovations for larger, formal and more institutionalised solutions should shift their focus from 'scaling up' particular solutions, to exploring and implementing ways to create encounters and reveal assumptions and contradictions implicit in these solutions by relocating them across cultural, social, organisational, technical and geographic boundaries.

\section{Note}

1. Discussion obtained from querying Twitter search website (http://twitter.com/search-home) using the keyword and hashtag GNIB. The tweets quoted above were posted between 2013 and 2014.

\section{Acknowledgement}

We would like to thank MyQ.ie, Code for Ireland and the participants for their generosity and thoughtful discussion along our research journey.

\section{Funding}

This work was supported by European Research Council Advanced Investigator [grant number ERC-2012-AdG-323636-SOFTCITY].

\section{References}

Anderson, W. (2002). Introduction: Postcolonial technoscience. Social Studies of Science, 32, 643-658. Retrieved from http://www.jstor.org/stable/3183050

Bissell, D. (2009). Conceptualising differently-mobile passengers: Geographies of everyday encumbrance in the railway station. Social and Cultural Geography, 10, 173-195. doi:10.1080/14649360802652137 
boyd, d., \& Crawford, K. (2012). Critical questions for big data: Provocations for a cultural, technological, and scholarly phenomenon. Information, Communication \& Society, 15, 662-679. doi:10.1080/136 9118X.2012.678878

Büscher, M., Liegl, M., Perng, S.-Y., \& Wood, L. (2014). How to follow the information? A study of informational mobilities in crises. Sociologica, 2014(1), 1-37. doi:10.2383/77044

Büscher, M., Urry, J., \& Witchger, K. (Eds.). (2011). Mobile methods. London: Routledge.

Central Statistics Office. (2011). CD619: Population usually resident and present in the state by nationality, sex, county of usual residence and census year. Cork: Author.

Chakrabarty, D. (2000). Provincializing Europe: Postcolonial thought and historical difference. Princeton, $\mathrm{NJ}$ : Prince University Press.

Coleman, E. G. (2013). Coding freedom: The ethics and aesthetics of hacking. Princeton, NJ: Princeton University Press.

Davies, S. R., Tybjerg, K., Whiteley, L., \& Söderqvist, T. (2015). Co-Curation as hacking: Biohackers in copenhagen's medical museion. Curator: The Museum Journal, 58, 117-131. doi:10.1111/cura.12102

de Laet, M., \& Mol, A. (2000). The Zimbabwe bush pump: Mechanics of a fluid technology. Social Studies of Science, 30, 225-263. doi:10.1177/030631200030002002

Dourish, P., \& Mainwaring, S. D. (2012). Ubicomp's colonial impulse. Proceedings of the 2012 ACM Conference on Ubiquitous Computing, 133-142. Retrieved from http://dl.acm.org/citation. $\mathrm{cfm}$ ? id $=2370238$

Edgerton, D. (2010). Innovation, technology, or history: What is the historiography of technology about? Technology and Culture, 51, 680-697. doi:10.1353/tech.2010.0007

Elden, S. (2006). National Socialism and the politics of calculation. Social \& Cultural Geography, 7, $753-$ 769. doi:10.1080/14649360600974741

Elwood, S. (2010). Geographic information science: Emerging research on the societal implications of the geospatial web. Progress in Human Geography, 34, 349-357. doi:10.1177/0309132509340711

Elwood, S., Goodchild, M. F., \& Sui, D. Z. (2012). Researching volunteered geographic information: Spatial data, geographic research, and new social practice. Annals of the Association of American Geographers, 102, 571-590. doi:10.1080/00045608.2011.595657

Elwood, S., \& Leszczynski, A. (2013). New spatial media, new knowledge politics. Transactions of the Institute of British Geographers, 38, 544-559. doi:10.1111/j.1475-5661.2012.00543.x

Forlano, L., \& Mathew, A. (2014). From design fiction to design friction: Speculative and participatory design of values-embedded urban technology. Journal of Urban Technology, 21, 7-24. doi:10.1080 /10630732.2014.971525

Gell, A. (1998). Art and agency: An anthropological theory. Oxford: Oxford University Press.

Gilmartin, M. (2013). Changing Ireland, 2000-2012: Immigration, emigration and inequality. Irish Geography, 46, 91-111. doi:10.1080/00750778.2013.794323

Goodchild, M. (2007). Citizens as sensors: The world of volunteered geography. GeoJournal, 69, 211-221. doi:10.1007/s10708-007-9111-y

Graham, M., De Sabbata, S., \& Zook, M. A. (2015). Towards a study of information geographies: (Im) mutable augmentations and a mapping of the geographies of information. Geo: Geography and Environment, 2, 88-105. doi:10.1002/geo2.8

Haklay, M. (2013). Neogeography and the delusion of democratisation. Environment and Planning A, 45, 55-69. doi:10.1068/a45184

Haklay, M., \& Weber, P. (2008). OpenStreetMap: User-generated street maps. IEEE Pervasive Computing, 7, 12-18. doi:10.1109/MPRV.2008.80

Harding, S. (1994). Is science multicultural? Challenges, resources, opportunities. Configurations, 2, 301-330. Retrieved from https://muse.jhu.edu/article/8039

Hine, C. (2000). Virtual ethnography. London: Sage.

Johnson, P., \& Robinson, P. (2014). Civic hackathons: Innovation, procurement, or civic engagement? Review of Policy Research, 31, 349-357. doi:10.1111/ropr.12074

Kitchin, R. (2014). The real-time city? Big data and smart urbanism. GeoJournal, 79(1), 1-14. doi:10.1007/ s10708-013-9516-8

Kitchin, R., \& Dodge, M. (2011). Code/space: Software and everyday life. Cambridge, MA: MIT Press. 
Kitchin, R., Lauriault, T. P., \& McArdle, G. (2015). Knowing and governing cities through urban indicators, city benchmarking and real-time dashboards. Regional Studies, Regional Science, 2, 1-28. doi:10.10 80/21681376.2014.983149

Levitas, J. (2013). Defining civic hacking. Code for America [Web page]. Retrieved from http://www. codeforamerica.org/blog/2013/06/07/defining-civic-hacking/

Levy, S. (1994). Hackers: Heroes of the computer revolution. London: Penguin.

Maalsen, S., \& Perng, S.-Y. (2016). Encountering the city at hacking events. In R. Kitchin \& S.-Y. Perng (Eds.), Code and the city (pp. 190-199). London: Routledge.

Mackenzie, A. (2006). Cutting code: Software and sociality. New York, NY: Peter Lang.

Marcus, G. E. (1995). Ethnography in/of the world system: The emergence of multi-sited ethnography. Annual Review of Anthropology, 24, 95-117. doi:10.1146/annurev.an.24.100195.000523

Mattern, S. (2013). Methodolatry and the art of measure: The new wave of urban data science. Places Journal. Retrieved from http://designobserver.com/places/feature/0/38174/

Mattern, S. (2014). Interfacing urban intelligence. Places Journal. Retrieved from https://placesjournal. org/article/interfacing-urban-intelligence/

Mattern, S. (2016). Instrumental city: The view from Hudson Yards, ca. 2019. Places Journal. Retrieved from https://placesjournal.org/article/instrumental-city-new-york-hudson-yards/

Mooney, P., \& Corcoran, P. (2012). Characteristics of heavily edited objects in OpenStreetMap. Future Internet, 4, 285-305. doi:10.3390/fi4010285

Morozov, E. (2013). To save everything, click here: Technology, solutionism, and the urge to fix problems that don't exist. New York, NY: Allen Lane.

Philip, K., Irani, L., \& Dourish, P. (2012). Postcolonial computing: A tactical survey. Science, Technology \& Human Values, 37, 3-29. doi:10.1177/0162243910389594

Pigg, S. L. (1992). Inventing social categories through place: Social representations and development in Nepal. Comparative Studies in Society and History, 34, 491-513. Retrieved from http://www.jstor. org/stable/178849

Powell, A. (2008). Wifi publics: Producing community and technology. Information, Communication \& Society, 11, 1068-1088. doi:10.1080/13691180802258746

Redfield, P. (2002). The half-life of empire in outer space. Social Studies of Science, 32, 791-825. doi:10.1177/030631270203200508

Rose, G. (2016). Rethinking the geographies of cultural'objects' through digital technologies: Interface, network and friction. Progress in Human Geography, 40, 334-351. doi:10.1177/0309132515580493

Sassen, S. (2012). Urbanising technology. Retrieved from http://lsecities.net/media/objects/articles/ urbanising-technology/en-gb/

Sheller, M. (2004). Mobile publics: Beyond the network perspective. Environment and Planning D: Society and Space, 22, 39-52. doi:10.1068/d324t

Söderström, O., Paasche, T., \& Klauser, F. (2014). Smart cities as corporate storytelling. City, 18, 307-320. doi:10.1080/13604813.2014.906716

Starbird, K., \& Palen, L. (2011). "Voluntweeters": Self-organizing by digital volunteers in times of crisis. Proceedings of the 2011 Annual Conference on Human Factors in Computing Systems, 1071-1080. Retrieved from http://dl.acm.org/citation.cfm?id=1979102

Starbird, K., \& Palen, L. (2013). Working and sustaining the virtual "Disaster Desk". Proceedings of the 2013 Conference on Computer-Supported Cooperative Work, 491-502. Retrieved from dl.acm.org/ citation.cfm?id=2441832

Suchman, L. (2011). Anthropological relocations and the limits of design. Annual Review of Anthropology, 40(1), 1-18. doi:10.1146/annurev.anthro.041608.105640

Sui, D., \& Goodchild, M. (2011). The convergence of GIS and social media: Challenges for GIScience. International Journal of Geographical Information Science, 25, 1737-1748. doi:10.1080/13658816.2 011.604636

Thrift, N. (2011). Lifeworldlnc - And what to do about it. Environment and Planning D: Society and Space, 29, 5-26. doi:10.1068/d0310

Townsend, A. M. (2013). Smart cities: Big data, civic hackers, and the quest for a new utopia (1st ed.). New York, NY:W.W. Norton.

Tsing, A. L. (2005). Friction: An ethnography of global connection. Princeton, NJ: Princeton University Press. 
Urry, J. (2007). Mobilities. Cambridge: Polity Press.

Urry, J. (2014). Networks, systems and futures. Keynote at the 10th Annual Cosmobilities Conference: Networked Urban Mobilities, Aalborg University \& Roskilde University, Copenhagen.

van Dijck, J. (2014). Datafication, dataism and dataveillance: Big Data between scientific paradigm and ideology. Surveillance \& Society, 12, 197-208. Retrieved from http://ojs.library.queensu.ca/index.php/ surveillance-and-society/article/view/datafication/datafic

Vanolo, A. (2013). Smartmentality: The smart city as disciplinary strategy. Urban Studies, 51, 883-898. doi:10.1177/0042098013494427

Verran, H. (2002). A postcolonial moment in science studies: Alternative firing regimes of environmental scientists and aboriginal landowners. Social Studies of Science, 32, 729-762. doi:10.1177/030631270203200506

Verran, H. (2010). Number as an inventive frontier in knowing and working Australia's water resources. Anthropological Theory, 10, 171-178. doi:10.1177/1463499610365383

Wiig, A. (2015). IBM's smart city as techno-utopian policy mobility. City, 19, 258-273. doi:10.1080/13 604813.2015.1016275

Wilson, M. W. (2011).'Training the eye': Formation of the geocoding subject. Social \& Cultural Geography, 12, 357-376. doi:10.1080/14649365.2010.521856 